Kirjallisuutta - References

H a h n, G. G. \& Ayers, Th. T., 1934: Dasy. scyphae on conifers in North America III. Dasyscypha pini. - Mycologia 26, p. 79501.

L a g e r b e r g, T., 1912: Studier över den norrländska tallens sjukdomar, särskilt med hänsyn till dess föryngring. (Studien über die Krankheiten der norrländischen Kiefer mit besonderer Rücksicht auf ihre Verjüngung. - Medd. fr. Stat. Skogsförsöksanst. 1.

Kanga s, Esko, 1937: Tutkimuksia mäntytaimistotuhoista ja niiden merkityksestä. (Untersuchungen über die in Kiefernpflanzenbeständen auftretenden Schäden und ihre Bedeutung). - Metsät. tutkimuslaitoksen julkaisuja 24.

Karsten, P. A., 1895: Fragmenta Mycologica XLIII. - Hedwigia XXXIV.
Kujala, Viljo, 1950: Über die Kleinpilze der Koniferen in Finnland. Ascomyctes, Fungi imperfecti, Uredinales. - Metsätieteellisen tutkimuslaitoksen julkaisuja 32. 4.

R e h m, H., 1896: Die Pilze Deutschlands, Oesterreichs und der Schweiz. III Ascomyceten: Hysteriaceen und Discomyceten. (In Rabenhort's Kryptogamenflora von Deutschland, Oesterreich und der Schweiz.) - Leipzig.

S a c card o, P. A., 1889: Sylloge Fungorum omnium hucusque cognitorum VIII. Patavii.

V a a r t a j a, O 11 i, 1951: Alikasvuasemasta vapautettujen männyn taimistojen toipumisesta ja merkityksestä metsänhoidossa. (On the recovery of released pine advance growth and its silvicultural importance). Acta forestalia fennica 53,3.

\title{
Boletinus asiaticus Sing. in Finnland gefunden.
}

\section{R. Tuomikoski.}

$\mathrm{Zu}$ den seltenen die Lärchen (Larix) begleitenden Röhrlingen gehört in Finnland der Hohlfussröhrling, Boletinus cavipes (Opat.) Kalchbr. Thesleff (1893, p. 70) entdeckte zuerst die Art in dem bekannten Lärchenforst von Raivola auf der Karelischen Landenge (seit 1944 nicht mehr finnisches Gebiet), reichlich unter Larix sibirica, und später fand $\mathrm{N}$ y ber $\mathrm{g}$ (1934, p. 20-21) sie in Porvoo, Vessö (U), an der Südküste Finnlands unter Lärchen zusammen mit dem bei uns gemeinen Goldröhrling (Suillus Grevillei = Boletus elegans).

Nyberg (1.c., Orig. schwedisch) berichtet über Boletinus cavipes in Porvoo: "Zwei verschiedene, deutlich getrennte Typen wurden gefunden - der eine gelbbraun von ziemlich fester Konsistenz und mit recht hellem gelbgrünem Sporenstaub - der andere mehr oder minder lebhaft karmin, von viel weicherer Konsistenz, mit viel grösseren und mehr unregelmässigen Poren als bei dem braungefärbten Typ und mit dunklerem und mehr braunem Sporenstaub. Sie wuchsen ungefähr an gleicher Stelle, doch in voneinander getrennten Gruppen".

Proben von beiden Typen liegen im Herbarium der Universität Helsinki (HMF). Die Sporen des karminfarbenen Boletinus sind deutlich dunkler und grösser (über 10 / lang und über $4 \mu$ breit, meist wohl 11-12 $\times$ $4.5-5 \mu$ ) als beim typischen B. cavipes.

Ein Fruchtkörper von demselben karminroten Boletinus wurde mir im September 1952 von Forstmeister Einari Vallela aus Sippola
(EK) zugesandt. Der Fundort war eine 60 jährige Lärchenanpflanzung von Oxalis-Myrtillus-Typ, mit dichtem Fichtenunterwuchs und spärlichen Kiefern in Sippola, Savero. Die Probe war am 13. IX. 1952 gesammelt. Als ich den Pilz erhielt, hatte er schon beträchtlich durch Fäulnis und durch Frass von Mückenlarven gelitten, doch liess die Probe noch eine Untersuchung der Hutoberfläche, sowie der Poren und Sporen zu. Die Übereinstimmung mit Nybergs Proben aus Porvoo auch S in g e r s (1938, p. 164-166) Originalbeschreibung und Abbildung von Boletinus asiaticus war so gut, dass ich es nicht für gewagt halte, die Proben von den beiden Fundorten mit der Singerschen Art zu identifizieren.

Singer (l.c.) erwähnt Boletinus asiaticus nur aus Nordasien (Tomsk, Altai-Gebirge, Transbaikalien und Amur-Gebiet), wo die Art unter Larix sibirica und $L$. dahurica "ad terram nudam, inter herbas et ad truncos", in den Gebirgen bis $2200 \mathrm{~m}$ vorkommt. - Die Art wäre somit für ganz Europa neu.

\section{Literatur:}

Nyberg, W., 1934: Några i Borgá och dess omnejd funna sällsyntare svamp-arter. Memor. Soc. F. Fl. Fenn. 10, 20-23.

S inger, R., 1938: Sur les genres Ixocomus, Boletinus, Phylloporus, Gyrodon et Comphidius. - Rev. de Mycol. (Nouv. Sér.) 3, $157-177$.

Thesleff, A., 1893: [... svampvegetationen i den planterade lärkträdskogen i Raivola...] - Meddel. Soc. F. FI. Fenn. 19, $70-71$. 